\title{
THE USE OF A METABOLOMIC APPROACH TO INVESTIGATE METABOLIC DIFFERENCES BETWEEN SEXES IN OVERWEIGHT ADOLESCENTS
}

\author{
Enrico A. R. Finardi, Renata G. Duft, Wendell A. Lopes, Mara Patrícia T. Chacon-Mikahil, Neiva Leite,Cláudia \\ Regina Cavaglieri
}

\begin{abstract}
Puberty cause changes in sex hormones, insulin sensitivity and endocrine functions that changes body composition and distinguish boys from girls. The systems biology has been widely used to study metabolism, especially the metabolomic approach, which identifies and quantifies metabolites, reproducing the physiological state of the organism. Therefore, the objective of this study is to use the metabolomics to investigate the metabolic differences among sex associated with obesity. The sample consisted of 40 adolescents of both sexes, between 13 and 17 years of age, who were overweight and obese (BMl between 25 and $34.9 \mathrm{~kg} / \mathrm{m}^{2}$ ) and was divided into 2 groups (male and female). After the blood collection, nuclear magnetic resonance (NMR) analysis procedures were performed. Significant differences were observed between the metabolites carnitine, glycerol and leucine among overweight men and women. Much of these differences are due to the differences in sex hormones and different amounts of accumulation of body fat.
\end{abstract}

\section{Key words: METABOLOMICS, SEXES DIFFERENCES, OVERWEIGHT}

\section{Introduction}

Puberty is the process of physical and endocrinal changes, such as body composition and sex hormones, that changes metabolism and distinguish men from women (STAIANO; KATZMARZYK, 2012). For a broad biological view of an organism, the use of Systems Biology and omics platforms are essential to a better biochemical knowledge of the metabolism. Metabolomics identify and quantify metabolites, which are small molecules with several metabolic functions. Thus, the objective of this study is to use metabolomic approach to investigate metabolic differences among sex associated with obesity.

\section{Results and Discussion}

A total of 40 adolescents with overweight and obesity were studied. The selected subjects were divided into: male group (MG $n=19$ ) and female group ( $F G n=21$ ). After the blood collection, nuclear magnetic resonance (NMR) analysis procedures were performed. An orthogonal partial last square discriminant analysis was conducted to construct a validated model with all samples. A segregation between sexes is observed in figure 1, and six metabolites were classified as best discriminators (carnitine, glycerol, succinate, ornithine, trimethylamine and leucine).

Higher concentrations of carnitine were found in boys compared to girls, and higher concentrations of glycerol and leucine in girls compared to boys. These differences occur in function of sex hormones (Opalka et al., 2001) and different body fat profiles between the sexes, as observed in table 1 (Rodriguez et al., 2015).

Table 1. Descriptive Variables

\begin{tabular}{ccc} 
Variables & GM $(\mathbf{n}=\mathbf{1 9})$ & GF $(\mathbf{n = 2 1})$ \\
\hline Age (years) & $14.21 \pm 1.18$ & $14.28 \pm 0.84$ \\
BMI $\left(\mathrm{Kg} / \mathrm{m}^{2}\right)$ & $27.15 \pm 3.69$ & $27.06 \pm 6.96$ \\
Fat Mass (\%) & $31.16 \pm 8.57$ & $42.5 \pm 6.88$
\end{tabular}

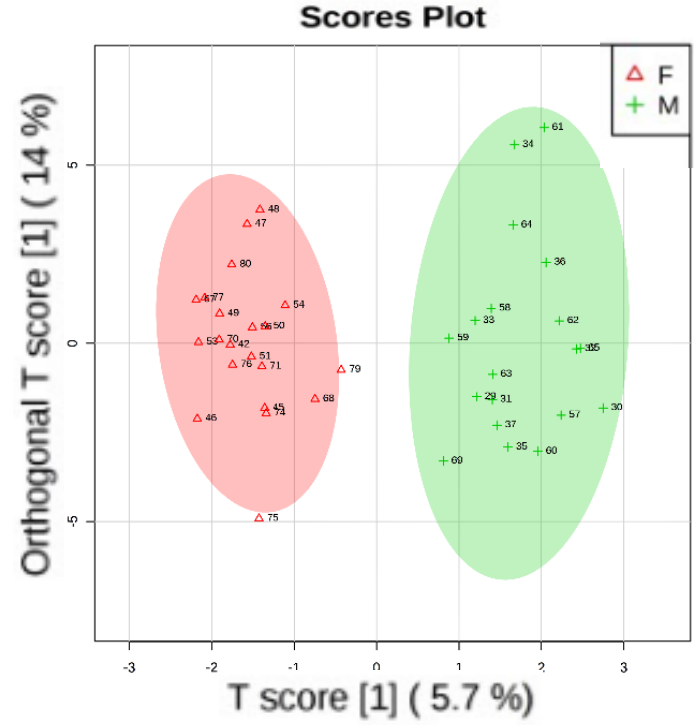

Figure 1. Orthogonal partial last square discriminant analysis (OPLS-DA) between MG x FG.

\section{Conclusions}

Differences were observed in some metabolites between overweight/obesity boys and girls. Much of these differences are due to differences in sex hormones and percentage of fat mass.

\section{Acknowledgement}

I thank PIBIC/CNPq for the scholarship, LNBio for the support and infrastructure, Araucaria Foundation for the financing, and UFPR for the partnership.

$\overline{\text { STAIANO, A. E.; KATZMARZYK }}$, P. T. Ethnic and sex differences in body fat and visceral and subcutaneous adiposity in children and adolescents. International Journal of Obesity, v. 36, n. 10, p. 1261-1269, 2012. OPALKA, J. R.; GELLERICH, F.; ZIERZ S. Age and Sex Dependency of Carnitine Concentration in Human Serum and Skeletal Muscle. Clinical Chemistry 47, No. 12, 2001

RODRÍGUEZ, Amaia et al. Sexual Dimorphism of Adipose and Hepatic Aquaglyceroporins in Health and Metabolic Disorders. Frontiers In Endocrinology, [s.1.], v. 6, p.1-7, 5 nov. 2815ı: 10.19146/pibic-2017-78448 XXV Congresso de Iniciação Científica da UNICAMP 